\title{
PALAVRA DESORDEM: OS JOGOS LEXICAIS DE ARNALDO ANTUNES
}

\section{PALAVRA DESORDEM: ARNALDO ANTUNES' LEXICAL GAMES}

\author{
Elis de Almeida CARDOSO ${ }^{1}$ \\ Sandra Mina TAKAKURA²
}

\begin{abstract}
Resumo: Este artigo tem por objetivo fazer uma análise dos jogos lexicais de Arnaldo Antunes em poemas publicados no livro Palavra desordem (2002), verificando-se de que forma, com suas experimentações poéticas, são obtidos os mais variados efeitos de sentido. Composta por poemas independentes, que lembram placas ou cartazes e valorizam o sintético e o lúdico, a obra arnaldiana pode ser lida em qualquer ordem e em diferentes direções. Pretendese aqui mostrar, em poemas escolhidos, como o autor brinca com a linguagem, ao trabalhar com as ressemantizações, a desagregação vocabular, a neologia, criando um estilo próprio.
\end{abstract}

Palavras chave: Arnaldo Antunes. Palavra desordem. Léxico. Estilo.

\begin{abstract}
This article aims at analyzing Arnaldo Antunes's lexical games in poems published in the book entitled Palavra desordem (2002), verifying in which ways the various effects of meaning are conveyed in his poetic experimentations. Composed by independent poems that recall us signs or placards and value the concision and playfulness, Arnaldo's works can be read through any order and in different directions. We intend to present in selected poems how the author plays with the language by working with resemantization, dismembering of words, neology, creating his own style.
\end{abstract}

Keywords: Arnaldo Antunes. Palavra desordem. Lexicon. Style.

1 Cardoso. USP. E-mail: elisdacar@usp.br. ORCID ID: https://orcid.org/0000-0002-8089-8716.

2 Takakura. UEPA. E-mail: sandramita@hotmail.com. ORCID ID: http://orcid.org/0000-0002-6882-0174. 


\section{Introdução}

O presente artigo tem por objetivo fazer uma análise de alguns poemas de Arnaldo Antunes, publicados em seu livro intitulado Palavra desordem (2002), verificando de que forma, com suas experimentações poéticas, são obtidos os mais variados efeitos de sentido.

Brincando com as palavras, aproveitando-se da paronímia, das ressemantizações, das desagregações e dos cruzamentos vocabulares, o poeta, por meio de jogos lexicais extremamente criativos, às vezes é crítico e irônico, outras vezes, parece fazer humor. Alguns de seus textos surgem em forma de conselho para o leitor que pode abrir o livro aleatoriamente em qualquer página e ler os poemas em qualquer direção.

Com letras tipográficas que lembram placas ou cartazes, utilizados na publicidade ou na política, Arnaldo Antunes apresenta nessa obra poemas minimalistas, que refletem toda sua criatividade e seu estilo. As placas/cartazes constituem um gênero discursivo que valoriza o impacto e a visualidade. Ao mesclar esse gênero basicamente informativo com o gênero poético, a obra do artista relaciona, no sentido descrito por Müller (2012), pelo menos duas mídias.

As relações entre cartaz e poesia são complexas devido ao nível de imbricamento das linguagens das mídias participantes. As obras analisadas podem, então, ser consideradas textos intermídias (CLÜVER, 2008, 2006; RAJEWSKY, 2012), fruto das intensas experimentações do poeta, uma vez que sofrem fusão, impossibilitando seu desmembramento.

Como objeto de análise deste artigo, selecionamos alguns de seus poemas, pelo fato de apresentarem criatividade e ludismo lexical. Nas obras escolhidas, Arnaldo Antunes vale-se dos jogos verbais, fazendo o uso de unidades lexicais distintas com sentidos similares, ou ainda fazendo uso de expressões cotidianas com o intuito expressivo.

Palavra desordem chama a atenção do leitor já em seu título, pela quebra da expressão "palavra de ordem". O sintagma "de ordem" é substituído pela forma derivada "desordem" (des- + ordem), constituída pelo prefixo de negação des-. O poeta antecipa, dessa forma, que os jogos lexicais constituem o eixo norteador de sua obra. O tema ou conceito do projeto centra-se, assim, na negação da ordem, da mensagem clara e transparente, preferindo-se no seu lugar uma linguagem concisa, como a das placas e cartazes, e opaca como a da poesia. 
Arnaldo Antunes, portanto, desenvolve o seu estilo, compreendido segundo Bakhtin (2016, p. 11-12), como "seleção dos recursos lexicais, fraseológicos e gramaticais da língua". Por meio dos jogos lexicais, constrói metáforas em poemas que aliam o visual e o sonoro, ocasionando renovações semânticas.

\section{Brincando com as palavras: os cruzamentos lexicais}

Os cruzamentos vocabulares (SANDMANN, 1992) ou lexicais, também chamados de amálgamas (PRUVOST-SABLAYROLLES, 2003), palavras-valise (ALVES, 1990), palavras portmanteau na acepção de Lewis Carroll (cf. MARTINS, 1997), e mais recentemente de blends, mesclagens lexicais (GONÇALVES, 2006) e fuves (BASÍLIO, 2010), são formados pela união entre dois vocábulos com um objetivo específico e um significado próprio.

Segundo Martins (1997, p. 123-124), "a sua formação revela criatividade, espírito, e sua força expressiva resulta da síntese de significados e do inesperado da combinação".

Os cruzamentos são, portanto, resultado de um processo em que unidades lexicais se mesclam formando outra unidade, sem, entretanto, manterem, obrigatoriamente seus radicais. "Mesclas são caracterizadas pela interseção de palavras, de modo que é impossível recuperar, através de processos fonológicos como crase, elisão e haplologia, as sequências perdidas" (GONÇALVES, 2006, p. 220).

O significado da nova formação está associado a várias questões culturais e comportamentais. Voláteis ou nem tanto, na grande maioria das vezes elas refletem a visão crítica e o humor gerado por um momento específico.

Pode-se dizer que há basicamente dois processos de formação dos cruzamentos vocabulares: por interseção de uma unidade em outra e por truncamento de uma ou das duas unidades componentes. Para que haja a interseção de uma unidade em outra é preciso haver entre as unidades uma correspondência fonológica, responsável pela soldagem que pode ser maior ou menor, dependendo do caso.

No discurso literário, escritores se aproveitam desse processo para criar unidades lexicais expressivas e inusitadas. Segundo Cardoso (2018, p. 244), "a atenção a esse processo deve voltar-se, principalmente, para a criatividade lexical, uma vez que se chama a atenção justamente para o inesperado resultante da combinação sintética".

Em Palavra desordem, Arnaldo Antunes faz uso desse processo, e formações como "superficialma", "rejuvelhecer" e "imagigabytes" são alguns exemplos de sua criatividade. 


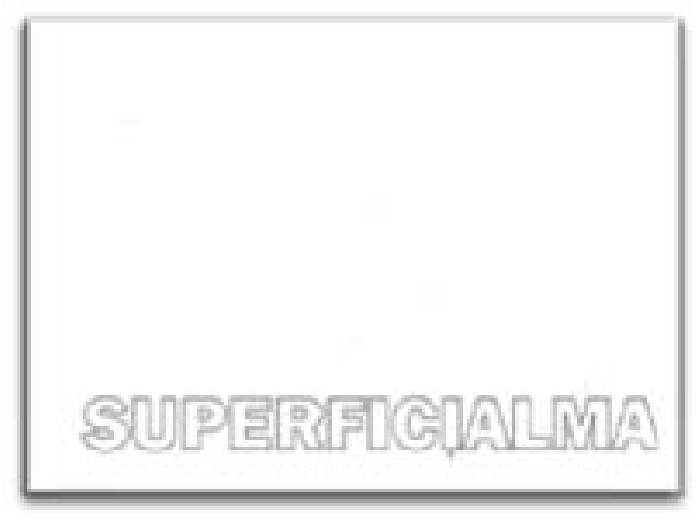

Figura 1. Superficialma

Fonte: Antunes (2002)

A formação "superficialma", única palavra do poema, pode ser explicada pelo processo de cruzamento lexical ocorrido entre as unidades lexicais "superficial" e "alma". A terminação "al" de "superficial" coincide foneticamente com a sílaba inicial de "alma", sendo perfeita a soldagem entre as duas palavras.

O processo de compreensão acerca da alma, índole e caráter demanda profundas reflexões sobre as atitudes humanas consideradas nobres e elevadas. Com a criação "superficialma", o acesso à alma do indivíduo está associado à superfície, opondo-se ao ato reflexivo aprofundado. A alma pode estar relacionada com o meio líquido. A profundidade dá lugar à superfície. O profundo passa a ser superficial. Tal noção paradoxal é reforçada pela disposição espacial da palavra na página impressa. Ocupando a base inferior, indica profundidade, opondo-se ao significado de superfície.

A arte é estruturada na relação oposta entre o verbal e o visual: entre a superfície verbalizada e a profundidade percebida na disposição espacial. Tal oposição provoca uma quebra na isotopia, por meio dessa combinação expressiva. A relação entre a profundidade e a superfície pode ainda remeter a duas outras noções espaciais, ao interior (alma) e ao exterior (superfície/corpo). Ocorre, portanto, a mescla entre a profundidade e a superfície, situadas em um espaço de input, e o interior (alma) e o exterior (corpo), situados em outro espaço de input (FAUCONNIER; TURNER, 2002).

Já "rejuvelhecer" estrutura-se através do cruzamento lexical entre duas bases com sentidos opostos, "rejuvenescer" e "envelhecer". A sílaba comum "ve" e o mesmo sufixo fazem com que haja a imbricação entre as duas unidades lexicais, dando resultado ao verbo neológico "rejuvelhecer". 


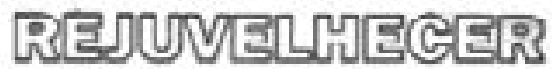

Figura 2. Rejuvelhecer

Fonte: Antunes (2002)

O cruzamento lexical ocorre em conjunto com a mesclagem conceitual a partir da projeção dos espaços de inputs ocupados distintamente por "rejuvenescer" e "envelhecer" (FAUCONNIER; TURNER, 2002). O sentido da criação lexical resulta da combinação de parte dos valores denotados nas unidades lexicais que lhe deram origem. Observam-se pelo menos duas noções temporais distintas. $\mathrm{O}$ envelhecimento pressupõe um tempo biológico em concordância com o tempo cronológico, ao passo que o rejuvenescimento supõe um tempo biológico em discordância com o tempo cronológico.

A criação explora uma nova forma de expressar a ideia do "rejuvenescimento" já conhecida. Contudo, ao imbricar as duas unidades lexicais, o poeta explora o processo de envelhecimento como sendo simultâneo ao de rejuvenescimento. Quanto mais a idade avança juntamente com o tempo cronológico, mais em termos cognitivos o indivíduo regressa aos estágios anteriores, em um processo similar ao de rejuvenescimento. Com o passar dos anos, o ser humano maduro torna-se mais dependente das pessoas ao seu redor, assemelhando-se à dependência da criança em relação aos seus responsáveis. $O$ poeta mostra que valores opostos e até mesmo conflitantes podem estar muito unidos e integrados no ciclo da vida.

A criação lexical "imagigabytes" resulta da fusão entre a unidade lexical "imagem" e o empréstimo "gigabyte". 


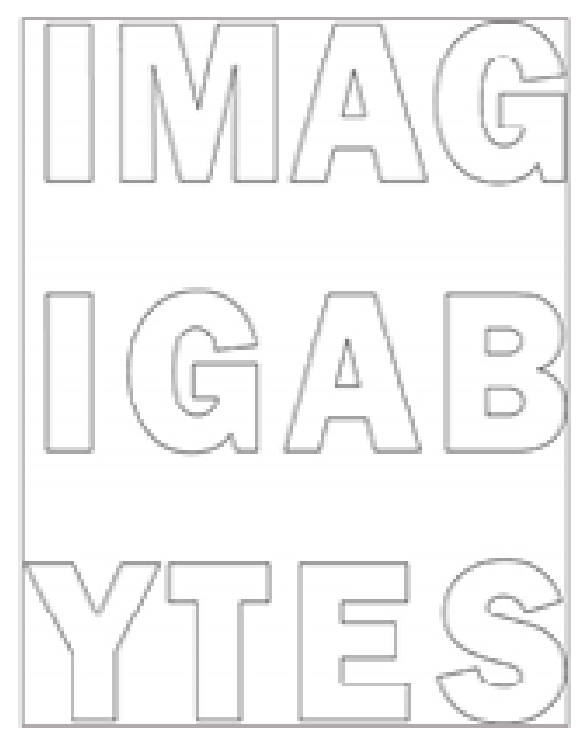

Figura 3. Imagigabytes

Fonte: Antunes (2002)

A imagem relaciona-se à memória visual humana associada à capacidade de reter e processar informações passadas e realizar projeções futuras. Já a unidade lexical "byte" pertence ao campo da tecnologia digital e se refere a uma unidade de memória de computador formada por 8 bits. A unidade "giga", por sua vez, refere-se a mil bytes de memória de um computador. A criação lexical permite ainda que se pense não só em "imagem", mas também em "imaginação" ou "imaginar".

$\mathrm{Na}$ criação, a memória humana mescla-se à memória de um computador, partindo de conceitos situados em espaços distintos de input (FAUCONNIER; TURNER, 2002). Ocorre a tensão entre o ato de imaginar, pautado na capacidade da memória humana, e o processamento de informação, baseado na memória do computador. No mundo tecnológico, a imaginação humana se processa por meio dos recursos digitais, responsáveis também pelas imagens.

\section{A desagregação vocabular: em busca do(s) significado(s)}

No mundo moderno e contemporâneo, as manifestações artísticas, e dentre elas a poesia, procuram muitas vezes apoiar-se na ruptura. A criatividade permeia o fazer poético na expressão da crítica e da ironia. Seja pelo uso do hífen, seja pelo aproveitamento das quebras dos versos, a desagregação vocabular revela os mais variados tipos de experimentação. As palavras deixam de ser lineares, despedaçam-se, produzindo 
incríveis efeitos de sentido. Formas comuns passam a ser substituídas por novas maneiras de construção do texto poético. O aproveitamento do espaço e dos sinais gráficos é característica forte em diversos autores modernistas e concretistas, dentre eles, Arnaldo Antunes. A expressão deixa de ser só linguística, apoiando-se principalmente, como quer o mundo moderno, na visualidade.

Segundo Cardoso (2018, p. 162):

A desagregação vocabular é responsável por um determinado efeito de sentido. À sonoridade soma-se o aspecto visual. Os poetas modernos e pósmodernos, que trabalham de forma integrada o som, a visualidade e o sentido das palavras, propõem, como os concretistas, uma nova maneira de pensar e de fazer poesia.

O poema a seguir configura-se espacialmente em duas páginas abertas no livro Palavra desordem.

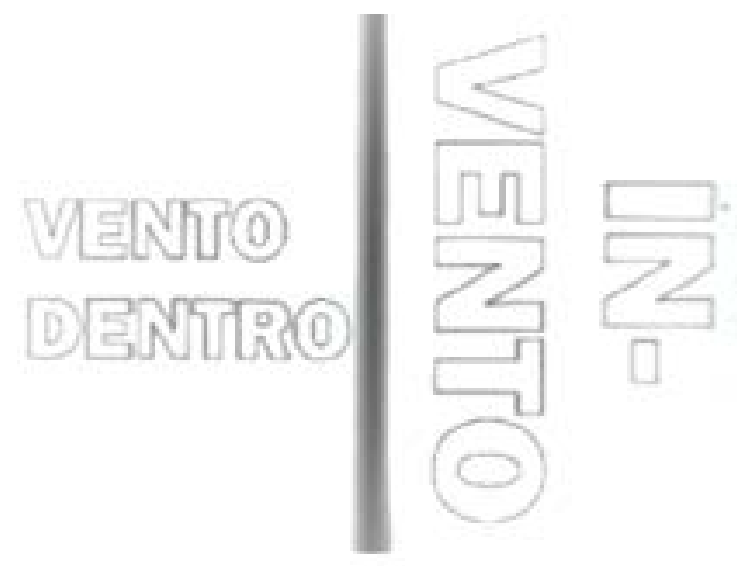

Figura 4. Vento dentro invento

Fonte: Antunes (2002)

As palavras ocupam distintos planos das páginas, sem a preocupação com a linearidade tradicional. A desagregação da palavra "invento" ("in-vento") faz com que sejam possíveis diversas possibilidades de interpretação. A presença do hífen pode marcar tanto a desagregação de "invento", que pode ser substantivo ou forma verbal flexionada em primeira pessoa, como também pode ser interpretada como resultante do processo de derivação prefixal (in- + vento), tendo o prefixo in- o sentido de "no interior; em". O poeta inicia o texto com "vento / dentro", indicando que o vento sopra no espaço interior. Sentido similar é obtido com "in-vento". Ocorre, portanto, a repetição da mesma ideia de vento interior através de construções distintas. 
O prefixo in- pode indicar também sentido negativo, portanto, a criação pode se referir tanto ao vento interior como à negação, ausência, do vento.

O vento interior, ou o sopro, pode também ser compreendido como a "alma" de um indivíduo, sua anima; "sopro, ar; princípio da vida; a alma, por oposição ao corpo" (HOUAISS; VILLAR, 2009, p. 97). Essa noção é reforçada pela formação "in-vento".

Podemos também ler o texto pensando em uma relação metapoética. O impulso criativo parte do interior e se aprofunda, produzindo a obra no exterior, através do vento interior que sopra na alma. Tal visão se relaciona com a noção de inspiração. O processo de criação parte do exterior ao interior, ou seja, de fora para dentro, tendo como resultado uma produção escrita, uma obra. O vento sopra de fora para dentro e, por meio dele, o poeta inventa, cria.

O hífen utilizado em "in-vento" é responsável por diferenciar o significado pretendido pelo poeta da palavra "invento" (substantivo ou verbo "inventar" flexionado). O substantivo "invento" indica o produto que resulta a partir da inspiração, ao passo que a forma flexionada do verbo "inventar" indica o processo criativo do eu. Partindo pelo hífen o "invento", o poeta mostra o quão difícil é a tarefa de inventar e produzir resultados. Muitas vezes nem sequer se chega à produção final.

A palavra "in-vento", resultante da desagregação da unidade lexical "invento", sendo compreendida seja como vento dentro, seja como não vento, seja como quebra do invento relaciona-se ao fazer poético e às dificuldades enfrentadas pelo poeta no processo de concepção da obra.

\section{Jogos lexicais: a exploração do som e do sentido}

O jogo sonoro obtido com a escolha de palavras parecidas é encontrado em alguns poemas de Arnaldo Antunes. Valorizando som e imagem, o poeta sabe aproveitar sua criatividade e produzir efeitos de som e sentido.

Esse jogo pode ser percebido com o uso das palavras "planeta" e "placenta", que apresentam convergência fonética. 


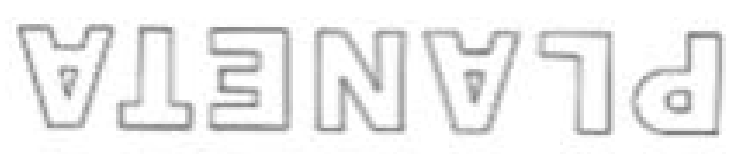

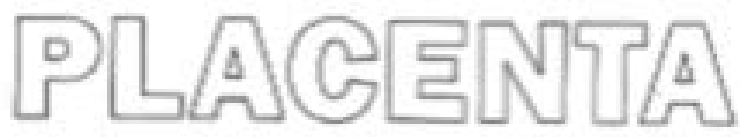

Figura 5. Planeta placenta

Fonte: Antunes (2002)

A água é o elemento comum presente no "planeta" azul, de forma abundante em rios, mares, oceanos, nuvens, gelos polares etc., e na "placenta", que remete ao útero onde se aloja a bolsa preenchida com o líquido amniótico que acomoda o feto.

"Planeta placenta" pode ser compreendida como uma composição sintagmática em que se unem "planeta" e "placenta", palavras com sons aproximados e sentidos diferentes. A disposição espacial da obra permite rotacioná-la, alternando as combinações entre "planeta placenta" e "placenta planeta", invertendo a relação determinado/ determinante.

Essa unidade lexical "planeta placenta" pode ainda ser analisada por meio da estrutura metafórica de domínio fonte e domínio (LAKOFF; JOHNSON, 2003 [1980]; FAUCONNIER; TURNER, 2002). O corpo feminino, relacionado à placenta, situa-se no domínio fonte e organiza o conteúdo do domínio alvo, o planeta vivo. O efeito expressivo resultante é o de um planeta gerador de vida. Já na configuração "placenta planeta", temse no domínio fonte o cosmos representado pelo planeta que organiza e estrutura o conteúdo do domínio alvo, a capacidade do corpo feminino de gerar a vida. O efeito criativo resultante é o de um corpo feminino gerador de vida no planeta. Essa alternância de sentidos permite ver a relação intrínseca entre o planeta e o corpo feminino e entre o corpo feminino e o planeta.

O "planeta" e a "placenta" situam-se em espaços de inputs distintos sendo projetados ao espaço de mescla. O corpo da mulher, gerador de vida, mescla-se, conceitualmente, ao próprio planeta, o espaço no qual toda a vida é gerada. A mescla resulta em uma redefinição conceitual de "planeta mãe" ou "mãe planeta" como espaço associado à geração de vida. 
O uso de palavras com sonoridade parecida e significado diferente pode ser encontrado também no poema "Cromossomo", em que há presença do jogo lexical entre "como", "cosmos", "comos", "somos", "cromossomos".

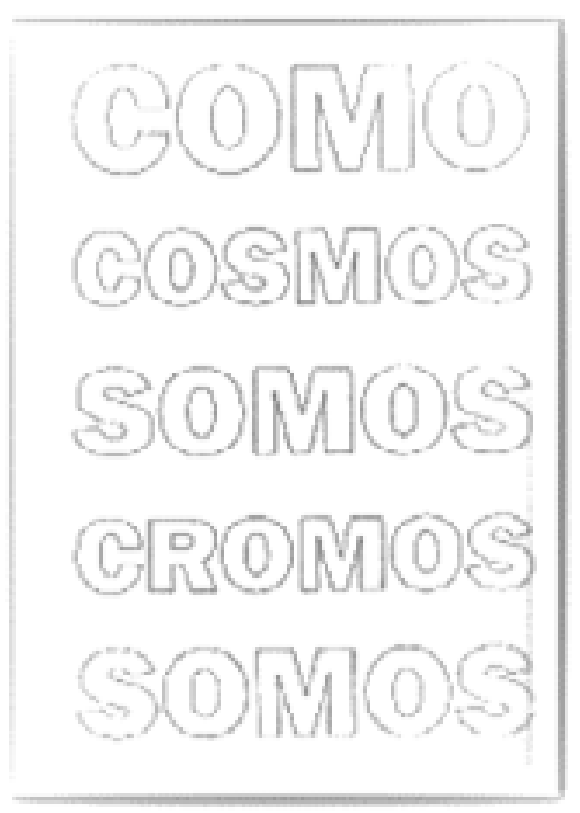

Figura 6. Cromossomo

Fonte: Antunes (2002)

O "cromossomo" faz parte do núcleo celular que guarda todo o patrimônio genético de um indivíduo, representando metonimicamente o ser humano. O macro e o micro se opõem no poema. De um lado o "cosmos" e do outro os "cromossomos". Na metáfora "somos cromos", a unidade lexical "cromo", de origem grega, denota "cor", o que reforça a ideia de multiplicidade de indivíduos e suas etnias e linhagens que se misturam para compor o patrimônio genético e cultural da humanidade, inserida no "cosmos". Trata-se, portanto, de uma nova forma de comunicar a conhecida informação sobre a mistura e a interação dos variados povos no planeta. O texto remete às perguntas que se referem à origem e ao fim da vida: de onde viemos e para onde vamos, ou ainda, quem somos.

\section{Re-leituras arnaldianas}

Muitos poetas modernos e contemporâneos brincam com as palavras, aproveitando-se seja da polissemia, seja da homonímia, seja dos trocadilhos para apresentar jogos lexicais extremamente criativos. Às vezes o objetivo é a crítica, outras vezes, simplesmente, o humor ou a ironia. O poema-piada, explorado pelos 
modernistas da primeira geração, surge como uma nova forma de poesia, apresentandose como uma provocação às formas tradicionais e rígidas. Mais adiante, os concretistas, aproveitando o espaço gráfico e os aspectos visuais brincam com o duplo sentido e com as ressemantizações.

Segundo Barbosa (1981, p. 231),

[...] ao procurar dar conta de uma análise da experiência, o sujeito falante, no processo da enunciação, atualiza uma unidade lexical, ou a substitui por outra, alterando a combinatória semêmica e desfigurando, em maior ou menor grau, a significação - entendida como valor de comunicação - a que se propunha.

As ressemantizações resultam em metáforas que quebram a expectativa do leitor por meio de combinações de itens lexicais com sons parecidos, ou ainda com substituições de itens lexicais com sentidos opostos. As ressemantizações e as releituras dos provérbios e frases feitas podem também ser destacadas como jogos lexicais. O poema "Em cada poro um beijo" pode ser explicado pela ressemantização da conhecida expressão "um amor em cada porto", ou ainda como variação da expressão "em cada boca um beijo".

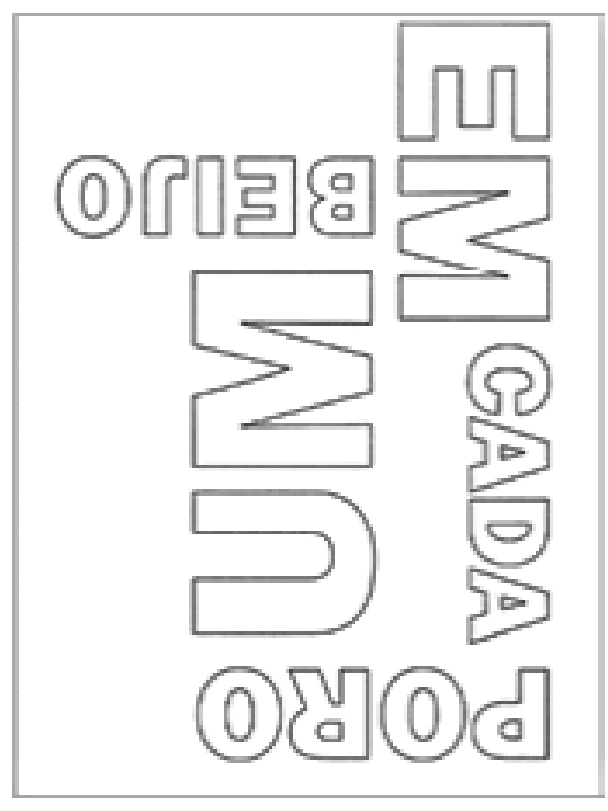

Figura 7. Em cada poro um beijo

Fonte: Antunes (2002)

O beijo pode ser entendido como uma forma de comunicação afetiva e semiótica que dispensa o uso de palavras. O beijo sugere afeto e carinho, que pode se estender 
para cada um dos poros do corpo. Os "poros" representam, então, cada uma das partes do corpo que pode ser beijada. A boca que beija é uma abertura do corpo, que entra em contato com outras aberturas de outro corpo.

O poema é estruturado em uma configuração espacial cíclica, quebrando a linearidade dos versos. O recurso da tipografia ressalta as unidades lexicais "em" e "um" em dimensões maiores, produzindo um efeito sonoro que imita a interjeição "hummmm", que exprime o prazer. Seu processo de leitura demanda que o leitor percorra com os olhos os versos no papel no sentido horário.

Mestre das ressemantizações, Arnaldo Antunes apresenta uma nova versão para o ditado "Quem não tem cão caça com gato", dizendo "Quem tem cão caça com cão".

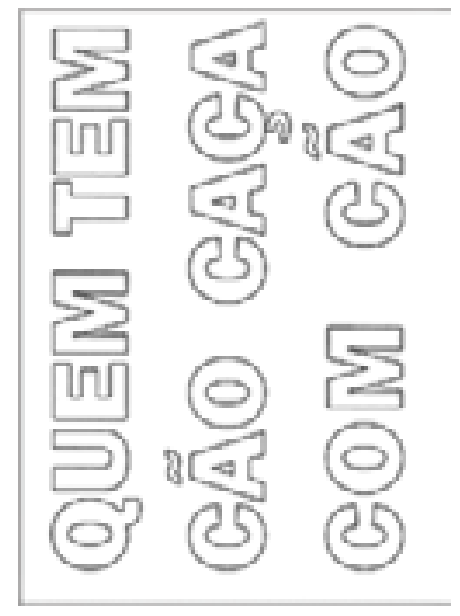

Figura 8. Quem tem cão caça com cão

Fonte: Antunes (2002)

O poeta valoriza o "ter" no lugar de "não ter", a presença ao invés da falta. A forma verbal "tem" é a única palavra do texto em que não ocorre o som [k] observado de forma recorrente em "quem", "cão", "caça" e "com", portanto se destaca. Na textualidade literária, observa-se que o efeito sonoro não se desvincula do efeito semântico, pois tais efeitos "podem estabelecer ligações complementares entre as palavras, ao se introduzir na organização semântica do texto" (LOTMAN, 1973, p. 167).

A falta estimula a criatividade, a sensibilidade e a habilidade de resolver questões e problemáticas de maneira alternativa, observado em "caça com gato" no lugar de "caça com o cão". Tal discurso está presente em falares populares que marcam a sapiência do indivíduo comum. No poema, Antunes brinca ao valorizar a posse, pois uma vez que o indivíduo está equipado com recursos e bens, deve necessariamente fazer uso dele. Com 
a posse, extingue-se a maneira criativa e compensatória de lidar com as dificuldades e questões no mundo.

O texto abaixo retoma a história de Ali Babá. Contrariando as expectativas do leitor, Antunes constrói a frase "Abre-te, cérebro", no lugar do esperado "Abre-te sésamo!".

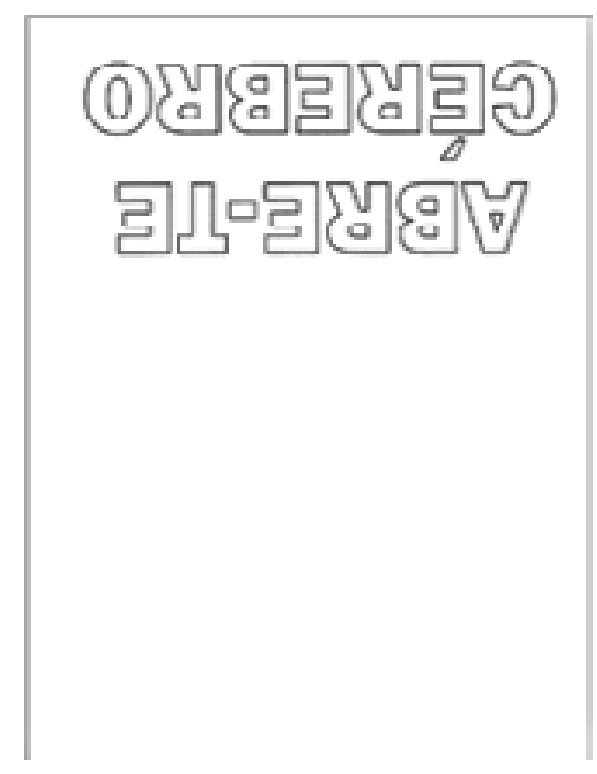

Figura 9. Abre-te, cérebro

Fonte: Antunes (2002)

Antunes espera que o leitor abra sua mente, seu cérebro, para mergulhar na poesia (tesouro) e compreendê-la. Convém notar que o texto ocorre na página do livro de cabeça para baixo. Embora a palavra "cérebro" esteja no alto da página, ela está invertida. O autor mostra, com isso, a importância de se ter um "cérebro". O cérebro encabeça a página, está no alto, no topo, mas invertido simboliza a não razão. É preciso ser racional e ter uma mente aberta. As palavras invertidas sugerem a ideia de contrariedade, o "cérebro" não pode estar invertido ou fechado, ele precisa se abrir como diz o poeta.

Em "O antídoto quer veneno", o jogo ocorre pela inversão da ordem sintática esperada, uma vez que um veneno requer um antídoto. 


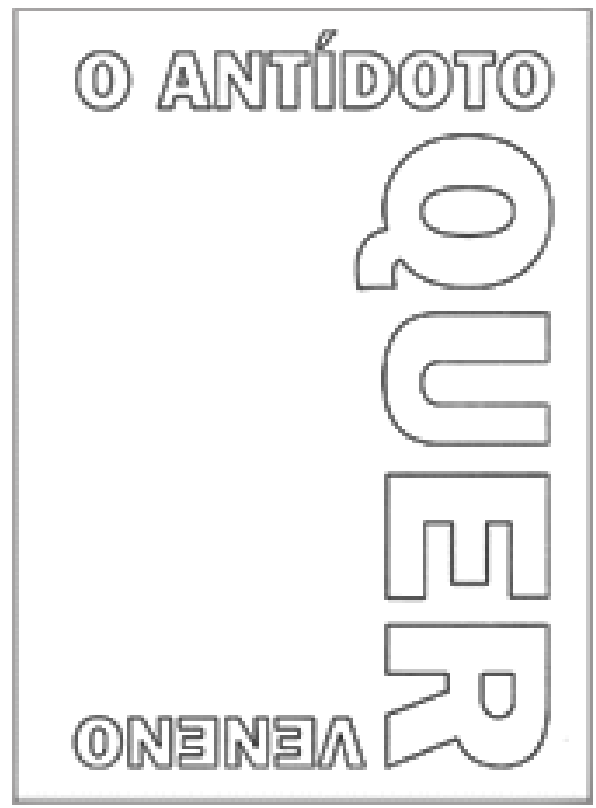

Figura 10. O antídoto quer veneno

Fonte: Antunes (2002)

Todo veneno necessita de um antídoto para anular o seu efeito. O veneno, na maioria das vezes, tem uma conotação negativa, uma vez que é algo que faz mal e pode matar. Já o antídoto tem a conotação positiva, uma vez que se refere à cura. No texto arnaldiano, o antídoto quer, portanto, deseja o veneno. O poeta parece mostrar ao leitor, com essa inversão de sentidos e de ordem, que até o antídoto precisa algumas vezes do veneno. Mesmo as coisas que fazem mal são desejadas pelas pessoas. O verbo "querer" aparece em tamanho bem maior, reforçando que o querer é imenso.

\section{Combinações inusitadas}

No exemplo a seguir, o poeta realiza inovações a partir da combinação de duas unidades lexicais que pertencem ao mesmo campo léxico-semântico como "fome" e "sede" em Fome de sede: 


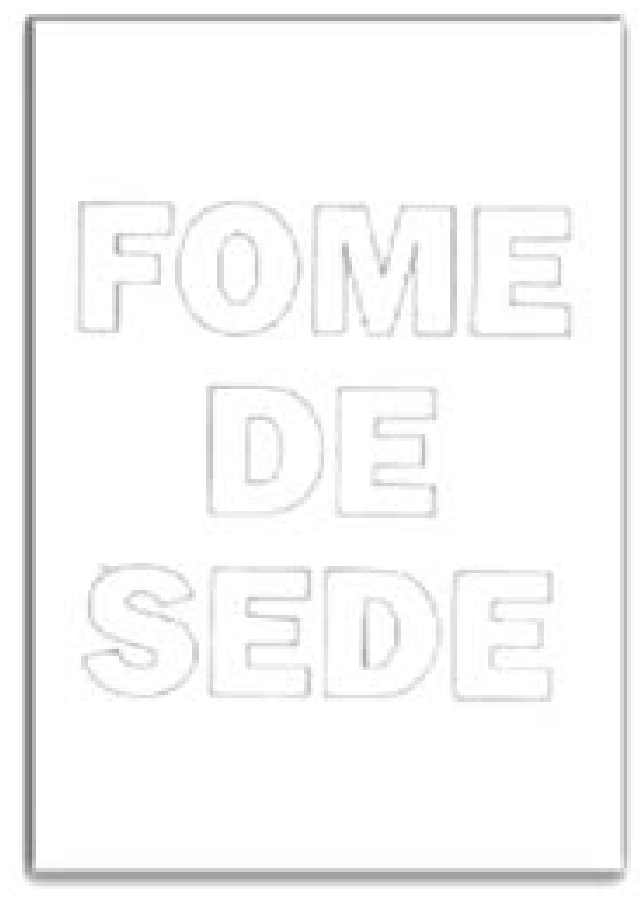

Figura 11. Fome de sede

Fonte: Antunes (2002)

No contexto do dicionário, a unidade lexical "fome" possui o significado de "necessidade ou desejo intenso; sofreguidão, avidez", comumente vista em construções cotidianas como "fome de conhecimento", "fome de carinho" e "fome de dinheiro" (HOUAISS; VILLAR, 2009, p. 913). A unidade lexical "sede" significa "desejo vivo, ardente, imoderado", que recorre no cotidiano por meio de metáforas como "sede de poder", "sede de cultura" e "sede de vingança" (HOUAISS; VILLAR, 2009, p. 1720). A construção "fome de sede" resulta de um jogo lexical entre as metáforas cotidianas estruturadas como "fome + de + nome" e "sede + de + nome".

Ambas as unidades lexicais, "fome" e "sede", relacionam-se paradigmaticamente, ocupando o mesmo espaço no eixo de seleção. Por isso, a escolha por uma unidade lexical necessariamente excluiria o uso da outra. A criatividade estilística do poeta ocorre pelo efeito de estranhamento obtido pela combinação inusitada entre as unidades lexicais "fome" e "sede" em "Fome de sede". A metáfora resulta da combinação imprevisível com o intuito expressivo (RIFFATERRE, 1971). Simultaneamente, o poeta indica, dessa forma, a ausência e a intensificação de sede.

No poema "Música subcutânea" a expressividade também é gerada pelo estranhamento. 


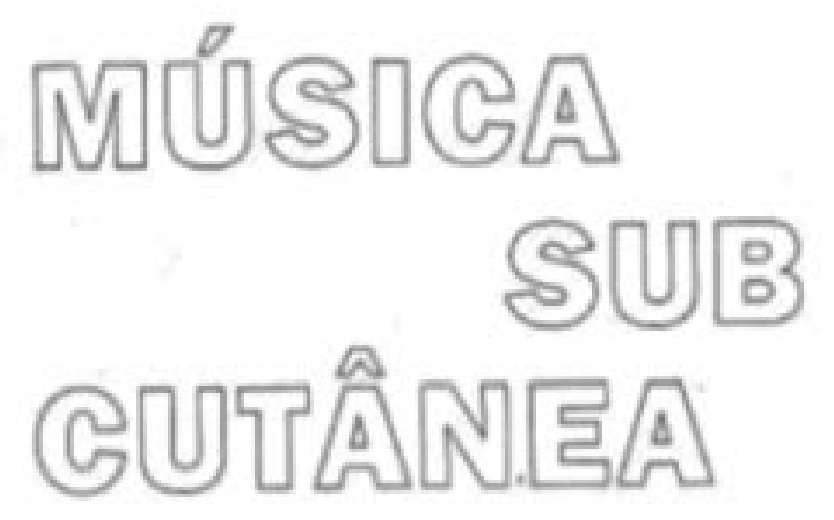

Figura 12. Música subcutânea

Fonte: Antunes (2002)

O poema pode ser compreendido segundo a estrutura sintagmática determinado + determinante, em que o adjetivo "subcutânea" qualifica o substantivo "música". Enquanto o adjetivo "subcutâneo" refere-se ao tato, o substantivo "música" ativa o elemento sensorial auditivo. Dessa forma, ocorre uma quebra de isotopia pela relação sinestésica entre as palavras.

A unidade lexical "subcutânea", situada no domínio fonte, estrutura e organiza o conteúdo de "música", situada no domínio alvo (LAKOFF; JOHNSON, 2003 [1980]). Usualmente, a unidade lexical "subcutânea", formada por meio do prefixo sub- ocorre em contextos médicos referentes aos procedimentos de aplicação de medicamentos (como a insulina introduzida) sob a pele para uma absorção mais lenta e prolongada. A música extrapola a audição e passa a ser sentida por debaixo da pele, estendendo-se ao corpo como um todo. Agrega-se à música a qualidade de medicamento necessário à manutenção da vida de um indivíduo. Com uma agulha, a música vai sendo administrada em doses contínuas, a partir de "furos" sob a pele e tal como uma tatuagem fica marcada profundamente na pele do indivíduo.

O sintagma "música subcutânea" permite estabelecer um contraste com a metáfora do cotidiano "sentir na pele", que indica a experimentação de alguma sensação de forma vívida. A experiência ressaltada através da combinação inusitada entre as unidades lexicais refere-se a algo para além da própria pele, com a possibilidade de penetração no corpo do indivíduo. A expressividade resultante da combinação não esperada das unidades lexicais produz o efeito de sentido (RIFFATERRE, 1971). 


\section{Considerações finais}

Os textos estudados foram produzidos por meio da convergência de mídias e apresentam um caráter minimalista. Sendo extremamente criativos, proporcionam ao leitor diferentes formas de leitura. Arnaldo Antunes desenvolve o seu estilo, por meio dos jogos lexicais e das escolhas que valorizam a plurissignificação.

A desagregação vocabular, aliada à distribuição espacial das palavras, criando espaços vazios e significativos permite pensar o jogo lexical e, portanto, o jogo semântico. Observou-se relação intrínseca do efeito sonoro e do efeito semântico (LOTMAN, 1973) nos poemas em que há cruzamentos lexicais ("superficialma", "rejuvelhecer" e "imagigabytes), desagregação ("cromossomo") e jogo sonoro e semântico ("planeta, placenta").

De forma expressiva, Arnaldo Antunes propõe um jogo semântico por meio do trocadilho entre palavras com sentidos opostos ("veneno" e "antídoto"), assim como em palavras com sons parecidos ("Sézamo", "cérebro"). As palavras "cão" e "gato" na obra do poeta indicam um trocadilho de ideias e de indivíduos e situações distintas. Assim como "poro" indica de forma polissêmica variadas partes do corpo do enunciatário.

O poeta ainda brinca com sentidos que podem simultaneamente se reforçar ou se anular em "fome de sede". As sensações da pele e além da pele se misturam em "música subcutânea", apontando novas formas de apreciação da arte.

Os exemplos apresentados resumem de forma absolutamente sucinta a criatividade do poeta. As possibilidades de comparações são infinitas, e os resultados surpreendem o leitor a cada nova compreensão da visão de mundo que está por trás dessas combinações inusitadas.

\section{REFERÊNCIAS}

ALVES, I. M. Neologismo - Criação lexical. São Paulo: Ática, 1990.

ANTUNES, A. Palavra Desordem. São Paulo: Iluminuras, 2002.

BAKHTIN, M. Os gêneros do discurso. Tradução de Paulo Bezerra da edição russa organizada por Serguei Botcharov. Rio de Janeiro: Editora 34, 2016 [1952-1953].

BARBOSA, M. A. Léxico, produção e criatividade: processos de neologismo. São Paulo: Global, 1981. 
- | Palavra desordem: os jogos lexicais de Arnaldo Antunes

BASÍLIO, M. Fusão vocabular expressiva: um estudo da produtividade e da criatividade em construções lexicais: textos selecionados. In: XXV ENCONTRO NACIONAL DA ASSOCIAÇÃO PORTUGUESA DE LINGUíSTICA. Porto: APL, 2010. p. 201-210.

CARDOSO, E. de A. O léxico no discurso literário: a criatividade lexical na poesia moderna e contemporânea. São Paulo: EDUSP, 2018.

CLÜVER, C. Inter textos / Interartes / Inter mídia. Aletria, v. 14, p. 11-41, jul.-dez. 2006. Disponível em: http://www.periodicos.letras.ufmg.br/index.php/aletria/article/ view/1357/1454. Acesso em: 20 out. 2019.

CLÜVER, C. Intermidialidade. Revista do Programa de Pós-graduação em Artes da Escola de Belas Artes da UFMG, v. 1, n. 2, p. 8-23, nov. 2008.

FAUCONNIER, G.; TURNER, M. The way we think: conceptual blending and the mind's hidden complexities. New York: Best Books, 2002.

GONÇALVES, C. A. Usos morfológicos: os processos marginais de formação de palavras em português. Gragoatá, Niterói, n. 21, p. 219-241, 2. sem. 2006.

HOUAISS, A.; VILLAR, M. de S. Dicionário Houaiss da língua portuguesa. Instituto Antônio Houaiss. Rio de Janeiro: Objetiva, 2009.

LAKOFF, G.; JOHNSON, M. Metaphors we live by. London: U. of Chicago Press, 2003.

LOTMAN, I. La structure du texte artistiques. Tradução Henri Meschonnic. Paris: Éditions Gallimard, 1973.

MARTINS, N. S. Introdução à estilística: a expressividade na língua portuguesa. São Paulo: Edusp, 1997.

MÜLLER, J. E. Intermidialidade revisitada: algumas reflexões sobre os princípios básicos desse conceito. In: DINIZ, T. F.; VIEIRA, A. S. (org.). Intermidialidade e Estudos Interartes: desafios da arte contemporânea 2. Belo Horizonte: UFMG, 2012. p. 75-95.

PRUVOST, J.; SABLAYROLLES, J. F. Les néologismes. Paris: PUF, 2003. 
RAJEWSKY, I. O. intermidialidade, intertextualidade e "remediação". In: DINIZ, T. F. N. (org.). Intermidialidade e Estudos interartes. Belo Horizonte: UFMG, 2012. p. 15-45.

RIFFATERRE, M. Estilística estrutural. Tradução Anne Arnichand e Álvaro Lorencini. São Paulo: Cultrix, 1971.

SANDMANN, A. J. Morfologia lexical. São Paulo: Contexto, 1992.

COMO CITAR ESTE ARTIGO: CARDOSO, Elis de Almeida; TAKAKURA, Sandra Mina. Palavra desordem: os jogos lexicais de Arnaldo Antunes. Revista do GEL, v. 16, n. 3, p. 72-90, 2019. Disponível em: https://revistadogel.gel.org.br/

DOI: http://dx.doi.org/10.21165/gel.v16i3.2756

Submetido em: 13/10/2019 | Aceito em: 02/12/2019. 